\title{
A New Approach to Understanding Contemporary Jewish Engagement
}

\author{
Janet Krasner Aronson ${ }^{1} \cdot$ Leonard Saxe $^{1} \cdot$ Charles Kadushin $^{1} \cdot$ Matthew Boxer $^{1}$. \\ Matthew A. Brookner ${ }^{1}$
}

Received: 9 July 2017 / Accepted: 8 October 2018 / Published online: 19 November 2018

(c) The Author(s) 2018

\begin{abstract}
Although researchers have long recognized the multidimensional nature of Jewish life (e.g., Hartman in Studies in Contemporary Jewry, Oxford University Press, New York, 2014; Himmelfarb in Understanding American Jewry, Brandeis University, Waltham, 1982), most sociodemographic studies examine Jewish behaviors and attitudes in isolation rather than considering their complex interactions. Examining each of these behaviors and dimensions separately provides only limited understanding of the meaning and enactment of Jewish identity. The present study presents a statistical method to understand the patterns of Jewish engagement across multiple dimensions. Based on data from a survey of the Greater Boston Jewish community, latent class analysis was used to combine 14 behavioral measures into a typology of Jewish engagement. The results were a "partially ordered" set of 5 classes representing distinct behavior patterns. Three of the classes followed a low-to-high continuum. Two classes did not follow this order and represented distinct but parallel patterns of engagement. Most notably, the study identified a category of Cultural Jews who do not regularly practice Jewish rituals or affiliate with synagogues but do feel strong connections to the Jewish community. A simple continuum of Jewish identity disguises the multidimensional nature of engagement and provides too simplistic a tool for policymakers. This approach suggests not only a new method of measuring Jewish engagement, but, more importantly, a new way to understand contemporary Jewish identity.
\end{abstract}

Keywords: Jewish engagement $\cdot$ Jewish identity $\cdot$ Survey research $\cdot$ Latent class analysis $\cdot$ LCA $\cdot$ Jewish community studies $\cdot$ Partially ordered

Janet Krasner Aronson

jaronson@brandeis.edu

1 Cohen Center for Modern Jewish Studies/Steinhardt Social Research Institute, Brandeis

University, Waltham, USA 
Local and national sociodemographic studies are important sources of information about Jewish identity and engagement of US Jews (Kotler-Berkowitz 2016). Sociodemographic studies are designed to describe and provide planning information about the size, characteristics, and engagement of US Jewry by measuring attitudes and behaviors of community members, including religious and cultural engagement, membership in Jewish institutions, support for Jewish charities, participation in Jewish education and programs, and more. Such measures are used to compare segments within and between communities and track changes over time (see examples at http://www.jewishdatabank.org/Studies/us-local-communities.cfm). Despite the multiple ways in which individuals engage in Jewish life, most sociodemographic studies categorize the construct of Jewish identity using labels that prioritize its religious dimension; for example, classifying the population as either "Jews by religion" or "Jews of no religion" (Kosmin et al. 1991; Pew Research Center 2013). Other studies use Jewish denominational affiliation as a principal distinction (Cox and Jones 2017; Pew Research Center 2017b).

Although researchers have long recognized the multidimensional and evolving nature of Jewish life (e.g., Hartman 2014; Horowitz 1998; Himmelfarb 1982), most sociodemographic studies examine Jewish behaviors and attitudes in isolation rather than considering interactions among them. This approach limits understanding the meaning and enactment of Jewish identity. Jewish identity interacts, as well, with a host of characteristics such as age, life stage, geography, economic and physical wellbeing, and more. Multivariate analysis furthers Jewish sociodemographic research by revealing the relationships among these individual measures and, consequently, identifying connected patterns of behavior and attitudes that exist across the diversity of US Jewry.

The present paper describes a new method of assessing Jewish identity and engagement. Rather than beginning with a preexisting scheme of how Jewish life is organized, the multivariate analytic approach allows categories to emerge from how Jewish survey respondents describe their Jewish behaviors. Using data from the 2015 Greater Boston Jewish Community Study, we use a statistical method, latent class analysis, to develop a typology of Jewish engagement patterns. After identifying patterns of Jewish engagement, we assess how this typology compares to other more commonly used Jewish background and attitudinal measures. We consider the question of how the patterns should be ordered: whether they represent a continuum from low to high engagement or, alternatively, a set of patterns that are different and parallel. Finally, we evaluate the robustness of the LCA method by applying it to other datasets.

\section{Categories of Jewish Identity}

Jewish denominational categories, at least in the past, have closely correlated with measures of Jewish engagement, including behaviors and attitudes. For this reason, denominational affiliation has been used as a proxy measure of behaviors, attitudes, and beliefs. Himmelfarb (1982) noted that "on every dimension of Jewish identification there is a similar rank ordering of denomination with Jewish identification" (p. 
72) with Orthodox Jews scoring highest on all measures, followed by Conservative, Reform, and then non-denominational Jews. Yet, Himmelfarb accurately predicted that " $\mathrm{t}]$ he efficacy of denominational self-identification as a measure of Jewish identification might dissipate over time" (p. 72). As an increasing number of Jews do not affiliate with any specific denomination (30\% in 2013; see Pew Research Center 2013), finding other ways to categorize and classify Jewish identification becomes more critical.

An alternative system for categorizing Jewish identity was developed by NJPS 1990 (Kosmin et al. 1991) and recently popularized by Pew's A Portrait of Jewish Americans (Pew Research Center 2013). Jewish respondents who indicated that Judaism was their religion were described as "Jews by religion (JBR)." Others who identified as Jewish but as having no religion were described as JNR, referred to as "Born Jews with no religion" in NJPS 1990 and in the Pew study as "Jews of no religion." In terms of Jewish engagement, including attitudes about being Jewish and perceptions of what it means to be Jewish, integration into the Jewish community, attendance at religious services, and practice of Jewish ritual and laws, the study reported that Jews by religion were far more likely to answer positively to questions on these issues than were Jews of no religion. The comparison of Jews by religion to Jews of no religion serves as the primary analytical framework for Pew's study report.

This religious classification obscures significant differences within and between these US Jews. Among all Jews, regardless of their JBR/JNR identification, $62 \%$ indicate that being Jewish is "mainly a matter" of ancestry and culture (Pew Research Center 2013). Only 15\% answer that being Jewish is "mainly a matter of religion." In fact, the majority (57\%) of Jews by religion consider Judaism to be mainly a matter of ancestry and/or culture, and an even larger share (83\%) of Jews of no religion share that view. Not surprisingly JBRs participate in religious behavior to a higher degree than do JNRs; nevertheless, there is considerable variation in participation in both religious and non-religious manifestations of Judaism within these groups. For example, Pew found that $70 \%$ of JBRs participated in a Passover seder in the previous year, as did a lower, but still substantial share of JNRs (42\%).

Pew (2013) utilized the JBR/JNR categories as its primary classification to analyze the study findings along a continuum from low to high Jewish identity. This schema was followed by almost all of the commentators on the report (e.g., Cohen 2015; Wertheimer and Cohen 2014). The interpretation of survey findings along religious lines led many observers to describe the results as distressing (e.g., Cohen 2015; eJewishPhilanthropy 2015; Wertheimer and Cohen 2014). Commentators highlighted findings that showed the proportion of self-identified Jews who observed traditional Jewish practices, ranging from lighting candles on Friday nights, attending Jewish services regularly, to keeping kashrut, as declining. Dire predictions about the future of US Jewry followed and posited that those who did not identify as Jewish by religion were unlikely to sustain their own Jewish identity or that of their children.

Despite widely held views of a Jewish community in decline, the evidence indicated that the overall size of the US Jewish community had increased in the past decades (Saxe and Tighe 2013; Saxe et al. 2014b). As discussed by Sheskin and 
Dashefsky (2017), "three different methods have recently produced estimates of the number of American Jews and all three are in general agreement" (p. 160). Although the proportion of adults who participated in Jewish rituals declined, Saxe et al. argued this finding was partly attributable to the increase in the number who identified as Jews of no religion (JNR): an increase of 69\% between 1990 and 2013, in comparison to $17 \%$ growth among Jews by religion (JBR) (Saxe et al. 2014a). One of the primary drivers of the rise in the population of Jews of no religion has been the increasing propensity of children of intermarried parents to identify as Jewish (Sasson et al. 2017).

The JBR/JNR terminology exhibits the same weakness as the denominational classification. By privileging religious attitudes and identification over other dimensions, the binary JBR/JNR classification oversimplifies Jewish identification and, therefore, has limited utility in explaining contemporary Jewish behavior.

An expansive perspective on Jewish identity and engagement is critical in light of the emergence of new and evolving Jewish organizations and practices, declining support for traditional Jewish institutions and behaviors, and the growing proportion of Jews who identify as JNR. Absent a corresponding analysis of alternative forms of Jewish engagement, it is impossible to determine whether Jewish life is, in fact, in decline or whether it is evolving into new forms. Capturing new forms of Jewish behavior and understanding their relationship to more traditional expressions of Judaism is challenging for researchers who seek to understand Jewish life through a standard set of survey measures.

\section{Latent Class Analysis as a Tool to Analyze Jewish Engagement}

To identify patterns of behavior from multiple responses, specialized statistical procedures are necessary. Using multivariate statistics to understand patterns of Jewish engagement is not novel, and there are a variety of techniques for combining multiple measures including factor analysis (e.g., Graham 2014; Hartman and Hartman 1996; Hartman et al. 2017), principal component analysis (e.g., Hartman and Sheskin 2012), similarity structure analysis (e.g., Hartman et al. 2017), and facet analysis (e.g., Rebhun 2004). A relatively simplistic approach to combining multiple measures, an additive index (e.g., Cohen et al. 2012), values each individual behavior equally and does not take into account the relationships among them. Other methods, such as factor analysis, utilize the correlations among variables to examine their relationships to one another, but do not categorize respondents according to their values for those variables. Those approaches develop classifications of variables rather than classifications of cases or respondents.

Latent class analysis (LCA) is one of a number of statistical tools that identify latent variables. Latent variables are hypothesized variables of interest that do not exist in the dataset but are measured indirectly through variables that can be included (i.e., observed or manifest variables). A classic example illustrates this relationship in which a third variable accounts for the association between two variables: the association between "the more firemen at a fire, the greater the damage," is explained by a third, omitted variable - the size of the fire. For the present 
analysis, "Jewish engagement" cannot be measured directly on a survey but is the latent variable of interest for the present study. We hypothesize that the behaviors that are used in this analysis, including ritual, institutional, and cultural measures, are observed characteristics that derive from Jewish engagement.

For the purpose of creating a typology of Jewish engagement, LCA (Henry and Lazarsfeld 1968) offers advantages over more commonly utilized statistical methods. LCA works with patterns and attempts to group them in such a way that within each group, or "class," there is no association between the patterns. Although the class is "latent" in that it does not actually appear in the variable set, the class accounts for the associations between the variables. LCA has been used to create typologies of related characteristics in the case of political views (Knight and Brinton 2017; Pew Research Center 2017a) and religion and spirituality (Kulis and Tsethlikai 2016; Pearce et al. 2013).

LCA has different goals than the more frequently used factor analysis (FA) (see IOM 2014). Both FA and LCA are designed to identify latent variables, but the types of latent variables that each method seeks to measure differ. The primary purpose of FA is data reduction or reducing the number of variables. FA identifies sets of variables that are related to one another because of a presumed underlying, latent variable. For example, if we were interested in knowing whether there was a latent "religiosity" variable and sought to identify which observed behaviors would best measure religiosity, we would utilize FA. This technique could be used to differentiate the behaviors that were associated with "religiosity" from those associated with, for example, "ethnicity" or "peoplehood." These factors could then be combined to categorize people based on their scores on each set. FA, however, does not provide a statistical basis for combining factors, nor does it establish a cutoff for "high" or "low" scores.

Rather than identifying groups of variables or characteristics, the goal of LCA is to identify classifications of people. The latent variable for LCA is a categorical variable representing multiple classes or types of people. Each individual is assumed to be a member of only one class. The LCA method determines, for each individual respondent, the probability of belonging to one of the classes identified by the LCA. This assignment is based on the pattern of responses to the observed variables used in the analysis. In LCA analysis, the typology of cases is based on statistical criteria.

The goal of the present study is to explicate the multidimensional nature of Jewish engagement, including its religious, cultural, and ethnic components. We hypothesize that there are distinct patterns of engagement with Judaism that can be found among members of the Jewish community. Unlike other types of classifications, we do not define a set of dimensions in advance, but instead examine the reported behavior and describe the patterns that emerge.

\section{Method}

The analyses discussed below were developed as part of the 2015 community study conducted for Combined Jewish Philanthropies (CJP), the Greater Boston Jewish Federation. Between April and August 2015, we surveyed 5,696 Jewish households 
Table 1 Behaviors included in index of Jewish engagement
Measure

Proportion of Jewish adults

$\begin{array}{ll}\text { Family holidays } & \\ \quad \text { Attended a seder } & 81 \\ \text { Lit Hanukkah candles } & 84 \\ \text { Ritual practices } & 11 \\ \quad \text { Keep kosher at home } & 17 \\ \text { Usually light Shabbat candles } & 12 \\ \text { Go to services three + times monthly } & 54 \\ \text { Attended High Holiday services } & \\ \text { Cultural activities } & 32 \\ \text { Listen to Jewish/Israeli music } & 33 \\ \text { Read Jewish/Israeli literature } & 44 \\ \text { Visit Jewish/Israeli websites } & 32 \\ \text { Seek out news of Israel often } & \\ \text { Communal practices } & 27 \\ \text { Dues-paying synagogue member } & 63 \\ \text { Attended a Jewish program in past month } & 24 \\ \text { Volunteered for Jewish cause in past year } & 66 \\ \text { Donated to Jewish cause in past year } & \end{array}$

Question wording and response options shown in "Appendix"

in the Greater Boston area using online and telephone modes of data collection (see Aronson et al. 2016).

To identify multiple dimensions of Jewish engagement, we incorporated a set of 14 behaviors that were included in the survey. These behaviors were divided into four categories of activities (Table 1), including family-based religious holidays, ritual practices, cultural consumption, and communal activities. The first category, family holidays, could have been included with ritual behavior but was separated due to its widespread observance in the Jewish community and the fact that, in many cases, participation in the holidays reflects secular or ethnic behavior rather than religious behavior (Gans 1979; Lazar et al. 2002). The third category, activities of cultural consumption, was differentiated not only because it included what can be called "popular culture" items, but also because these activities do not require institutional or organizational affiliation for participation. For the items that were asked on a four-point scale, each one was dichotomized so that only frequent behavior was included. The exact wording of each item is shown in the "Appendix Table 7".

A Stata plugin (Lanza et al. 2015) was used to implement LCA for the weighted dataset. One challenge in LCA is to determine the appropriate number of classes. To compare model fit, we used "Adjusted BIC" (Adjusted Bayesian Information Criterion), one of a number of test statistics that evaluate the fit of multiple models and adjust for sample size. The model with the lowest Adjusted BIC is considered to be the best-fitted model. Starting with two classes and advancing to multiple classes, we compared the Adjusted BIC for each number of classes to determine an 
4500

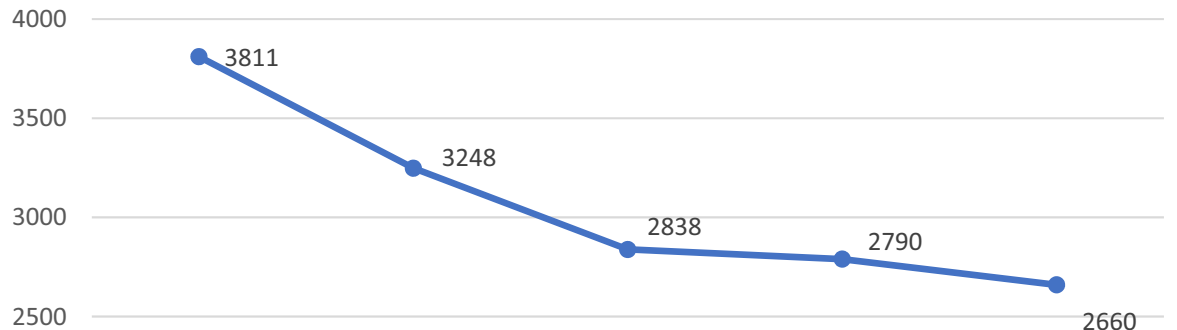

2000

1500

1000

500

0

Two class

Three class

Four class

Five class

Six class

\section{Adjusted BIC}

Fig. 1 Scree chart of Boston latent class analyses

inflection point that results in a fit that also yields the most apt interpretation. The resulting scree chart (Figure 1) shows the measures of fit for each of the two to seven classes. The adjusted BIC of the four, five, and six class solutions were similar, but the five-class solution was the most easily interpreted. ${ }^{1}$

\footnotetext{
${ }^{1}$ The Stata plugin as well as the standalone Mplus (https://www.statmodel.com/) allow for much more complexity than we have used here, including the modeling of covariates. To introduce LCA we have tried to keep the application and illustration of it as simple as possible. The same approach, not introducing covariates in the model but later exploring their relationship to the latent classes, was used in Knight and Brinton (2017). Stata incorporated LCA into its core package in version 15 which was released after this analysis was conducted. The authors found, however, that the LCA plugin was easier to use than the version within Stata 15.
} 


\section{Results}

The resulting LCA classes are shown in Table 2. The names given to the classes (as is the case with FA) reflect our interpretation of the patterns of behavior that are prevalent within each class and distinguish one class from another. The percentages shown in the header row of Table 2 are the proportions of Jewish adults in each class within the Boston Jewish population, as estimated by the LCA. The remaining rows of Table 2 indicate the proportion within each class that participated in the listed behavior. For example, the Minimally Involved class comprised $17 \%$ of the adult Jewish population, with $0 \%$ attending a seder but $33 \%$ lighting Hanukkah candles.

\section{Partial Ordering of Classes}

When we compare three of the classes, Minimally Involved, Familial, and Immersed, we can observe a continuum from low to high engagement for most or all behaviors. However, this order does not apply to the Affiliated and Cultural. When comparing these two classes, some measures are higher for the Affiliated, while others are higher for the Cultural. This "partial ordering" confirms the expectation that engagement is not a single continuum but a multidimensional construct. The partial ordering results from the identification of a Cultural group that scores higher on items related to the cultural dimension and an Affiliated group that scores higher on items of Jewish affiliation.

Below is a brief description of each of the engagement classes.

\section{Lower Engagement Groups}

The Minimally Involved, constituting $17 \%$ of Boston's Jews, and the Familial, with $24 \%$ of Boston's Jews, comprise the largely unaffiliated portion of the community that has little contact with Jewish institutions and organizations. When considering some typical indicators of Jewish engagement, such as synagogue membership and ritual practice, those in the Minimally Involved and Familial engagement groups demonstrate the lowest levels of engagement. Nonetheless, both groups include individuals who participate in Jewish life in some ways. At the same time, there are notable differences between the groups.

\section{Minimally Involved}

Jewish adults who fall into the Minimally Involved pattern do little or nothing in the way of Jewish activities and rarely affiliate with Jewish organizations. Virtually none are synagogue members, and none participate in the most popular home-based Jewish ritual, a Passover seder. Almost one quarter (24\%) of those in this group do none of the 14 listed behaviors. Nonetheless, Jewish adults who are Minimally Involved do occasionally participate in Jewish events and 


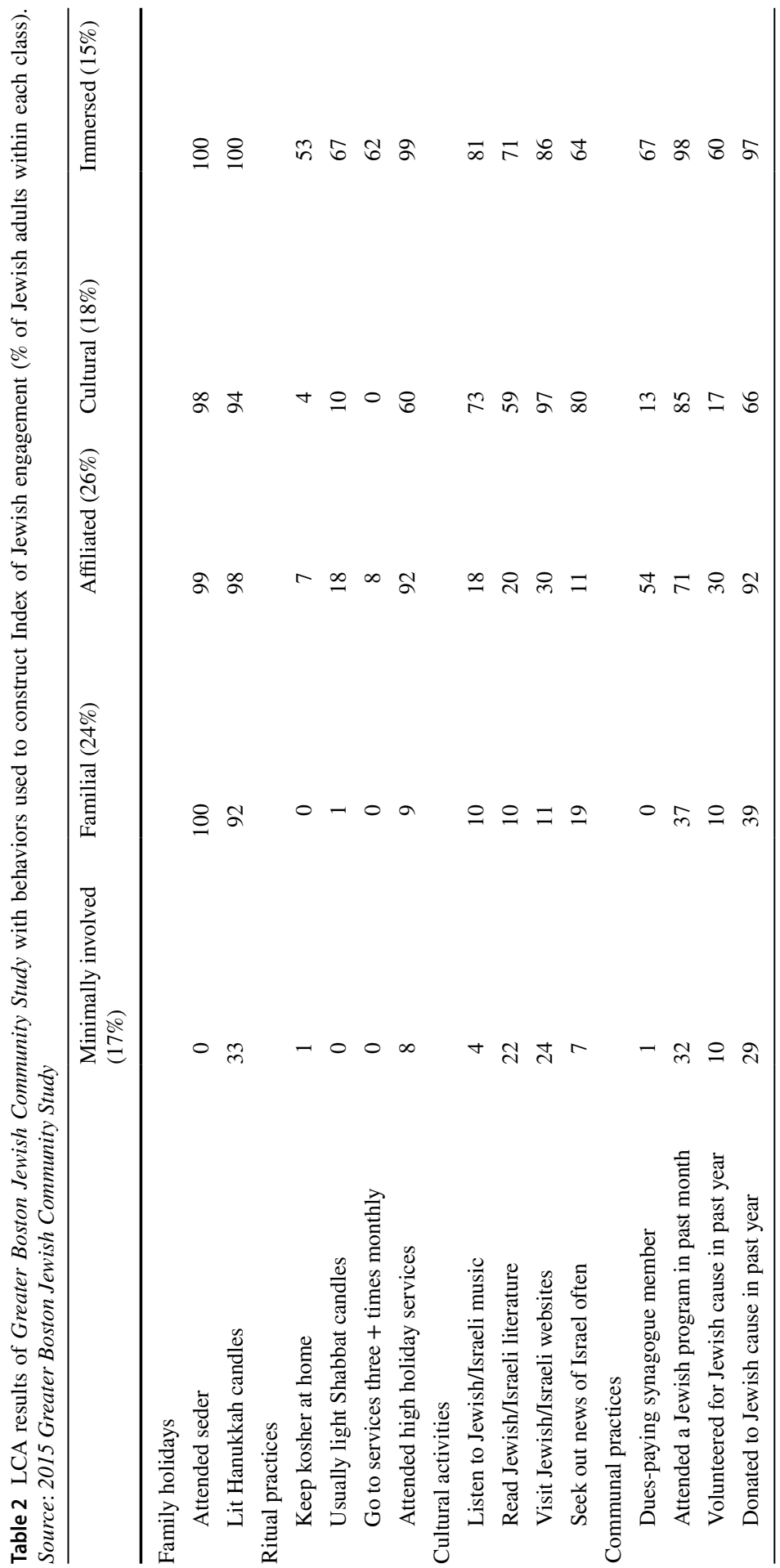


activities - they are not totally disconnected. One third (32\%) attended a Jewishsponsored program in the past month, and $29 \%$ donated to a Jewish charity in the past year.

\section{Familial}

Jewish adults in the Familial engagement pattern incorporate Judaism into their lives through home- and family-based rituals that do not involve institutional participation or commitment. For example, none are dues-paying synagogue members, and only 9\% attend High Holiday services. In contrast, nearly all attend Passover seders and light Hanukkah candles. Familial Jews participate in the community around them but do not focus on Jewish life. For example, less than half donated (39\%) to Jewish causes, and one-in-ten volunteered for a Jewish organization.

\section{Moderate Engagement Groups}

The Affiliated and Cultural engagement patterns represent two distinct ways of expressing engagement with Jewish life in which commitment is strong but not a central aspect of daily life. Nearly all Affiliated and Cultural Jewish adults light Hanukkah candles and attend Passover seders. Although only $18 \%$ of the Affiliated and $10 \%$ of the Cultural Jews usually light Shabbat candles, about two thirds of each group light Shabbat candles at least occasionally (not shown in the table). The majority of both groups attended at least one Jewish program in the past month. Nonetheless, the differences between these patterns of engagement are striking.

\section{Affiliated}

Affiliated Jews are more strongly tied to Jewish institutions, particularly synagogues, than are Cultural Jews. More than half (54\%) of Affiliated Jews are dues-paying synagogue members compared to $13 \%$ of Cultural Jews. More than nine-in-ten of the Affiliated attended High Holiday services in the prior year, compared to six-in-ten of the Cultural. As an indicator of support for Jewish institutions, nearly all in the Affiliated engagement pattern (92\%) made a donation to a Jewish cause in the past year.

\section{Cultural}

In comparison to Affiliated Jews, fewer Cultural Jews are dues-paying members of a Jewish congregation (13\%) or attended a High Holiday service (60\%). Cultural Jews tend to participate in Jewish life through personal activities rather than institutional connections. For example, almost all use the Internet to seek out information about Judaism and Israel. Three quarters listen to Jewish or Israeli music, over half read Jewish or Israeli books, and $80 \%$ follow news about Israel closely. 
Table 3 Jewish characteristics of LCA classes (\% of Jewish adults within each class). Source: 2015 Greater Boston Jewish Community Study)

Minimally $\quad$ Familial (24\%) $\quad$ Affiliated (26\%) $\quad$ Cultural (18\%) $\quad$ Immersed (15\%) involved

$(17 \%)$

\begin{tabular}{|c|c|c|c|c|c|}
\hline \multicolumn{6}{|c|}{ Jewish identification } \\
\hline JBR & 43 & 63 & 97 & 84 & 98 \\
\hline $\mathrm{JNR}^{\mathrm{a}}$ & 57 & 37 & 3 & 16 & 2 \\
\hline Total & 100 & 100 & 100 & 100 & 100 \\
\hline \multicolumn{6}{|c|}{ Denominational identification } \\
\hline Orthodox & $<1$ & $<1$ & 1 & 2 & 21 \\
\hline Conservative & 3 & 9 & 25 & 16 & 39 \\
\hline Reform $^{\mathrm{b}}$ & 10 & 27 & 55 & 25 & 25 \\
\hline None/other & 87 & 64 & 19 & 57 & 15 \\
\hline Total & 100 & 100 & 100 & 100 & 100 \\
\hline \multicolumn{6}{|l|}{ Inmarriage $^{c}$} \\
\hline Inmarried & 15 & 34 & 62 & 66 & 87 \\
\hline \multicolumn{6}{|l|}{ Children } \\
\hline $\begin{array}{l}\text { Has children at } \\
\text { home }\end{array}$ & 21 & 30 & 41 & 25 & 35 \\
\hline $\begin{array}{l}\text { Raising children } \\
\text { Jewish (of } \\
\text { those with } \\
\text { children) }\end{array}$ & 3 & 79 & 96 & 93 & $>99$ \\
\hline \multicolumn{6}{|l|}{ Friends } \\
\hline $\begin{array}{l}\text { Most/all close } \\
\text { friends Jewish }\end{array}$ & 10 & 17 & 36 & 38 & 66 \\
\hline
\end{tabular}

${ }^{a}$ Includes Jewish and another religion

${ }^{\mathrm{b}}$ Includes Reconstructionist and Renewal

${ }^{\mathrm{c}}$ Individual intermarriage rate, of those married or partnered

\section{Highest Engagement Group}

\section{Immersed}

Judaism is central to the lives of Jewish adults in the Immersed engagement group. Two thirds (67\%) are dues-paying synagogue members. Nearly all attended at least one Jewish program in the past month and donated to a Jewish cause in the past year. Two thirds closely follow news about Israel, and all attend High Holiday services. Not everyone in this group, however, is "religious" in the ritual sense. Just over half (53\%) keep kosher at home. Two thirds usually light Shabbat candles (67\%) and attend Shabbat services almost weekly (62\%). 


\section{Validating the Classes}

To validate the interpretation and ordering of the classes produced by the LCA, we compare the classes with other measures of Jewish identity that were not used in creating the typology. Those measures, shown in Table 3, map onto the five classes in expected ways but are consistent with the partial ordering of the classes. In particular, the comparison of the two moderately engaged groups reflects the partial ordering. Although they are similar in many of the factors that are associated with Jewish identity, the Affiliated exhibit stronger Jewish identity in some characteristics, while the Cultural demonstrate stronger Jewish identity with others.

For all Jewish characteristics in Table 3, there is an expected increase in identity for the three ordered engagement groups (Minimally Involved, Affiliated, and Immersed). For example, regarding Jewish identification, JBR (Jews by religion) characterizes just over $40 \%$ of the Minimally Involved, $63 \%$ of the Familial, and $98 \%$ of the Immersed. Similarly, $87 \%$ of the Minimally Involved have no denominational affiliation, as do $64 \%$ of the Familial and $15 \%$ of the Immersed. In contrast to the sequence in the ordered engagement groups, these measures of Jewish identification are stronger for the Affiliated than for the Cultural. Nearly all (97\%) of the Affiliated are JBR compared to $84 \%$ of the Cultural; $19 \%$ of the Affiliated have no denomination compared to $57 \%$ of the Cultural.

For those who are married, their inmarriage status follows the partial ordering. Among Immersed Jews, $87 \%$ who are married have a Jewish spouse, compared to $15 \%$ of the Minimally Involved and $34 \%$ of the Familial. The individual intermarriage rates for the Affiliated (62\%) and Cultural (66\%) are nearly identical. Over nine-in-ten of those in the moderate and high engagement classes are raising their children Jewish, but that rate is far less for those in the low engagement classes; $79 \%$ of the Familial are raising their children Jewish and just 3\% of the Minimally Involved.

The Jewish friendship networks of the classes also follow the partially ordered pattern. Two thirds $(66 \%)$ of the Immersed report that all or most of their close friends are Jewish, compared to $17 \%$ of the Familial and $10 \%$ of the Minimally Involved. Within the two moderate engagement groups, the proportion of Jewish friends is also similar, with $36 \%$ of the Affiliated and $38 \%$ of the Cultural reporting that most or all of their close friends are Jewish.

Attitudes about being Jewish are also partially ordered. To illustrate the similarities and differences in attitudinal measures across the classes, Figure 2 compares attitudes about being Jewish, and Figure 3 compares feelings of Jewish connections. As shown in Figure 2, the percent of each group that strongly agrees increases for each engagement group. However, the Affiliated and Cultural are very similar on these measures.

In contrast to the attitudes about being Jewish show in Figure 2, the differences between the moderate engagement groups are more dramatic on measures of feelings of connection to Jewish communities locally, in Israel, and worldwide (Figure 3). As is expected, Minimally Involved Jewish adults tend to have weaker 
- Part of daily life $₫$ Child marrying Jew important $\square$ Jewish grandchildren important $100 \%$

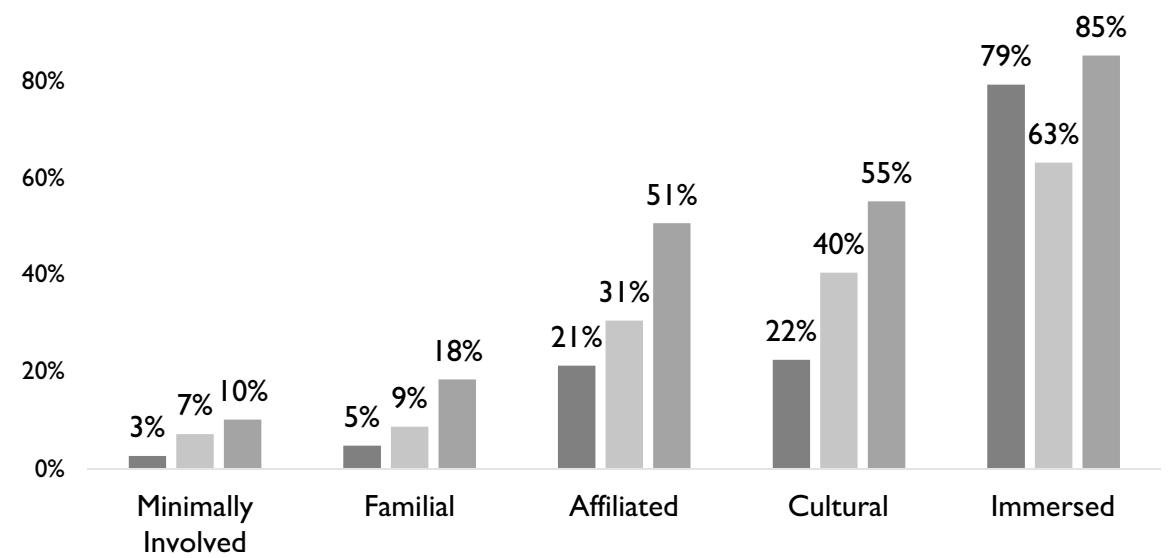

Fig. 2 Attitudes about being Jewish of LCA classes (\% of Jewish adults within each class) (\% very much agree that Judaism is part of daily life, \% very important that child marries someone Jewish, \% very important that grandchildren raised Jewish). Source: 2015 Greater Boston Jewish Community Study

-Worldwide $\square$ Israel $\square$ Local

$100 \%$

$80 \%$

$60 \%$

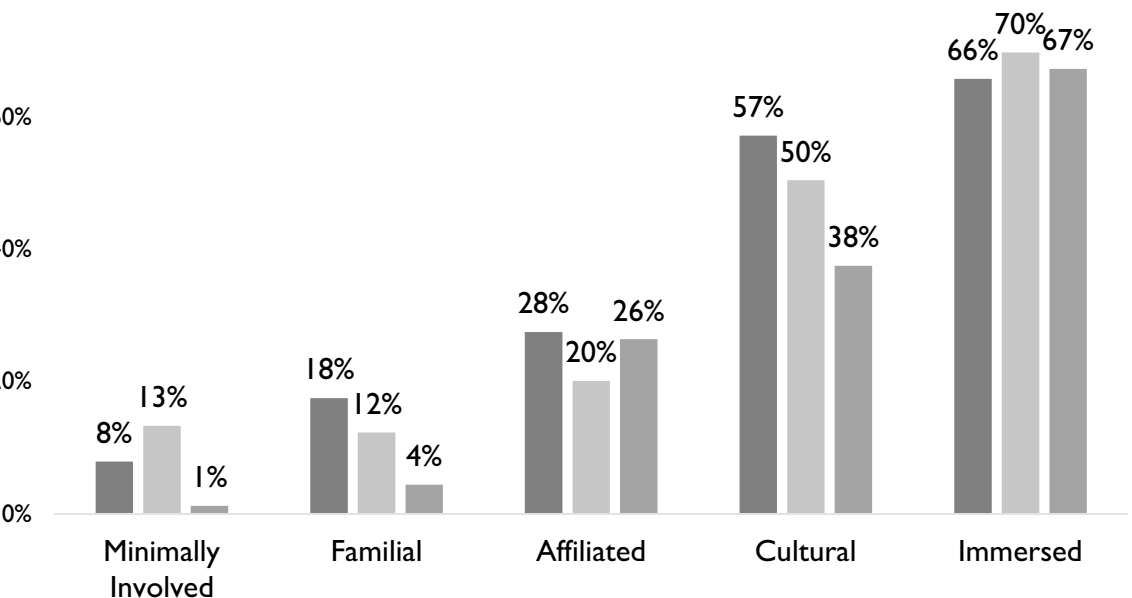

Fig. 3 Jewish connections of LCA classes (\% very much connected to worldwide Jewish community, Israel, and local Jewish community). Source: 2015 Greater Boston Jewish Community Study) 
Table 4 LCA Boston results classes without cultural items (\% yes within each class)

\begin{tabular}{llll}
\hline & Low (33\%) & Medium (48\%) & High (20\%) \\
\hline Family holidays & & & \\
$\quad$ Attended seder & 43 & 99 & 100 \\
$\quad$ Lit Hanukkah candles & 55 & 97 & 100 \\
Ritual practices & & & \\
$\quad$ Kosher & 0 & 4 & 45 \\
Shabbat candles & 0 & 9 & 64 \\
Services three + times monthly & 0 & 2 & 55 \\
High holiday services & 7 & 67 & 99 \\
Communal practices & & 30 & 66 \\
Synagogue member & 0 & 73 & 95 \\
Jewish program & 28 & 22 & 54 \\
Volunteered & 10 & 78 & 96 \\
$\quad$ Donated & 27 & & \\
\hline
\end{tabular}

attachments to the Jewish community, both locally and worldwide, and to Israel, than do Jews with other behavior patterns. Similarly, in the Familial engagement group, Jewish adults feel relatively weak attachments to the local and worldwide Jewish community. Immersed Jews are strongly connected to the worldwide and local Jewish community and to Israel.

Affiliated Jews, despite their Jewish institutional affiliations, are less likely to feel very connected to the local and worldwide Jewish community, including Israel, than are the Cultural group Jews. In comparison to those with the Affiliated pattern, those in the Cultural pattern are far more likely to feel very connected to the local Jewish community, the worldwide community, and to Israel.

\section{Other Applications of LCA}

To assess the utility and robustness of the LCA methodology for studying Jewish engagement, we conducted several additional LCA analyses. Our primary goal was to determine the impact of incorporating the cultural behaviors along with the other behaviors in the LCA analysis. Our secondary goal was to compare LCA to other techniques for creating an index. Our hypothesis was that the absence of the cultural items would yield a more unidimensional scale. To test this, we ran an LCA analysis in three ways: on the Boston dataset omitting the cultural items; on the Pew dataset that did not include cultural items; and on the dataset from the 2011 New York Jewish Community Study, comparing the results with the reported additive index.

When we re-ran the LCA for the Greater Boston study without the cultural items, a three-class solution fit very well, and the analysis yielded a simple low-mediumhigh continuum of Jewish engagement (Table 4). The latent class sizes show that $20 \%$ of Boston Jews are high in Jewish engagement, 33\% are low, and the remaining $48 \%$ are in the middle. Key items defining the continuum are High Holiday services and synagogue membership, consistent with a traditional view of Jewish 
Table 5 LCA reanalysis of Pew's Portrait of Jewish Americans, 2013 (\% yes within each class)

\begin{tabular}{lrlc}
\hline & Low (39\%) & Medium (46\%) & High (15\%) \\
\hline Remembering Holocaust & 56 & 75 & 80 \\
Leading ethical and moral life & 53 & 73 & 91 \\
Observing Jewish law & 8 & 21 & 58 \\
Working for justice and equality & 41 & 65 & 71 \\
Being intellectually curious & 36 & 55 & 54 \\
Caring about Israel & 23 & 56 & 74 \\
Being part of a Jewish community & 4 & 25 & 70 \\
Strong sense of belonging to Jewish people & 32 & 89 & 100 \\
Being Jewish is important in life & 8 & 48 & 96 \\
Responsibility to take on Jews in need & 29 & 81 & 97 \\
Emotionally attached to Israel & 5 & 32 & 73 \\
Kosher in home & 7 & 23 & 64 \\
Refrain from handling money on Shabbat & 3 & 12 & 48 \\
Seder & 23 & 62 & 97 \\
Usually light Shabbat candles & 1 & 14 & 73 \\
Fast on Yom Kippur & 12 & 55 & 93 \\
No Christmas tree & 36 & 60 & 96 \\
Went to Israel two+ & 4 & 14 & 56 \\
Went to services once twice month+ & 1 & 13 & 77 \\
Member of a synagogue & 0 & 18 & 78 \\
Member of a Jewish organization & 1 & 11 & 46 \\
Financial donation to Jewish cause & 9 & 59 & 96 \\
\hline
\end{tabular}

engagement. In this model, all individual items were ordered as expected, with the fewest share agreeing in the low engagement category and the largest share in the high engagement category. This three-class model is fully, rather than partially, ordered.

LCA, nonetheless, offers two advantages over other classification methods even in this case. First, it provides a statistical means for combining multiple uncorrelated measures. Second, it provides a statistical basis for determining cutoff points for low, medium, and high values rather than the eyeball procedure for simple additive scales. Despite these benefits, the multidimensional aspect of the Jewish engagement was not evident without the cultural measures.

\section{Pew Study of Jewish Americans}

The importance of cultural behaviors reflecting a variety of ways of acting "Jewishly" is underscored by an analysis of the 2013 Pew study of Jewish Americans (Pew Research Center 2013). Using a large selection of items, we developed a threeclass model of Jewish engagement: low, medium, and high, as shown in Table 5 below. Given the available measures, a more complex multidimensional model did 
Table 6 LCA reanalysis of Jewish Community Study of New York, 2011 (\% yes within each class)

\begin{tabular}{lllll}
$\begin{array}{l}\text { Minimally } \\
\text { involved } \\
(30 \%)\end{array}$ & Familial (22\%) & $\begin{array}{l}\text { Affili- } \\
\text { ated } \\
(17 \%)\end{array}$ & Ritual (13\%) & Immersed (19\%) \\
\hline
\end{tabular}

\begin{tabular}{|c|c|c|c|c|c|}
\hline \multicolumn{6}{|l|}{ Family } \\
\hline Seder & 22 & 85 & 84 & 88 & 100 \\
\hline Hanukkah & 21 & 81 & 76 & 96 & 99 \\
\hline \multicolumn{6}{|l|}{ Ritual } \\
\hline Friday night meal & 8 & 19 & 48 & 92 & 97 \\
\hline Services monthly & 1 & 0 & 19 & 36 & 81 \\
\hline Shabbat candles & 2 & 7 & 12 & 84 & 95 \\
\hline Kosher & 9 & 4 & 14 & 69 & 91 \\
\hline \multicolumn{6}{|l|}{ Cultural } \\
\hline Adult education & 6 & 5 & 64 & 17 & 90 \\
\hline Text study & 17 & 14 & 52 & 30 & 87 \\
\hline Talk about Jewish matters & 16 & 25 & 53 & 63 & 85 \\
\hline Museum & 22 & 41 & 85 & 35 & 74 \\
\hline \multicolumn{6}{|l|}{ Communal } \\
\hline Synagogue & 2 & 28 & 62 & 66 & 98 \\
\hline Program & 12 & 30 & 68 & 18 & 47 \\
\hline Organization & 3 & 10 & 41 & 21 & 63 \\
\hline Volunteer & 9 & 11 & 52 & 13 & 80 \\
\hline Donate & 17 & 55 & 87 & 68 & 98 \\
\hline
\end{tabular}

not reasonably fit. The results were comparable to the LCA analysis of the Boston data without the cultural behaviors, above. As with the Boston data, this model demonstrates the usefulness of LCA even when the underlying dimension seems unidimensional. What proportion of US Jews are highly Jewishly engaged? The model suggests about $15 \%$.

\section{New York Jewish Community Study}

The 2011 New York Jewish Community Study (Cohen et al. 2012) attempted to recognize multiple subjective ways of expressing Jewish engagement by introducing a typology of being Jewish that included cultural items. The New York study combined 12 items using a single-dimensioned additive index ranging from 0 to 12 . Eighteen percent affirmed none or only one of the items (p. 118). The authors also noted that those with minimal scores tended to endorse items not included in the scale that were more cultural and did not require "formal affiliation or collective action." While recognizing the multidimensional aspects of Jewish engagement, the study still reported its main findings in a unidimensional scale split into five categories at arbitrary cutpoints on a low-to-high continuum. 
Reanalyzing the New York data with LCA, using behaviors similar to those in the Boston study, a five-class latent structure fit (Table 6). Despite a number of similarities, one striking difference with the Boston results is evident: there is no clear cultural category. Instead, there is what we called a "Ritual" class, relatively high on most ritual items, but low on cultural items except for "talk about Jewish matters." An "Immersed" class is high on almost everything. Whether this represents a difference between New York and Boston or a difference in the way items were worded is difficult to know without replicating the Boston items in a New York survey.

\section{Discussion}

To assess the complexity of Jewish identity, the present study describes the development of a behavior-based typology of Jewish engagement. Based on 14 behavioral measures of Jewish engagement, including participation in home-based rituals, religious rituals, cultural activities, and communal activities, Latent Class Analysis (LCA) was utilized to identify five patterns of Jewish behavior. To validate these classes, the composition of classes was compared to more commonly utilized categories of Jewish life, including JBR/JNR and Jewish denomination, as well as characteristics that are associated with Jewish identity such as intermarriage, raising Jewish children, and having Jewish friends. Attitudes about the importance of being Jewish were also compared across the classes. The classes yielded a typology that was consistent with these other measures.

Three of the classes, the lowest two and the highest, reflected a low-to-high continuum of Jewish engagement, with other Jewish background and attitudinal measures correlating as expected with Jewish engagement. As hypothesized, two classes emerged that did not follow this continuum, representing distinct patterns of Jewish engagement. Neither can be described as "more" or "less" than the other; rather they are different and parallel. We refer to this condition as "partial ordering."

One implication of these findings is that formal affiliation with Jewish institutions, particularly synagogues, is not necessarily as strong a marker of Jewish identity as it is often considered. Although the Affiliated join and support Jewish organizations, this connection does not appear to translate into bringing Judaism into the home or developing emotional connections to the Jewish community. In contrast, those in the Cultural group, though less likely to be dues-paying members of synagogues, feel far more connected to the local and worldwide Jewish communities and to Israel than those in the Immersed group. Because these individuals are less affiliated with Jewish institutions, their strong Jewish connections and behaviors are frequently overlooked.

In order to assess the general applicability of the LCA method, we ran three comparison models. An LCA of the Boston dataset excluding the cultural items demonstrated their importance for a full understanding of Jewish engagement. In contrast to the partially ordered model that included the cultural items, a simple low-to-high engagement continuum appeared when they were excluded. Similarly, the LCA of the Pew dataset, which did not include cultural items, yielded a three-class low-tohigh typology. 
The New York dataset, which incorporated cultural items, resulted in a five-class structure that was similar to the Boston five-class typology. This typology offers more nuance and utility than the additive index presented in the study report. More exploration is needed to determine whether the difference between the New York and Boston results is a reflection of differences in question wording or due to underlying differences in the composition of each Jewish community.

\section{Conclusion}

The ways in which contemporary Jews engage with their Jewish identities vary; and, so too, should our approach to studying them. To encompass the complexity of contemporary Jewish experiences in a large community study, Latent Class Analysis (LCA) used measures of Jewish engagement that included survey responses dealing with culture, community, nationality, and religious practices. Understanding Jewish engagement in these terms provides a more complex and nuanced view of Jewish engagement and raises questions that are relevant not only to survey researchers who seek to measure Jewish engagement, but also to community leaders who seek to promote it.

This approach suggests not only a different method of measuring Jewish engagement, but, more importantly, a new framework to understand contemporary Jewish life. A simple low-to-high continuum of Jewish involvement disguises its multidimensional nature and provides too simplistic a tool for policymakers who wish to promote and enhance Jewish engagement. Most notably, the 2015 Greater Boston Jewish Community Study identified a category of Cultural Jews who do not regularly practice Jewish rituals or affiliate with synagogues but do feel strong connections to the Jewish community. At the same time, the study identified a category of Affiliated Jews who join synagogues and support institutions but do not feel strong emotional ties to the Jewish world. These findings illustrate the way in which a more complex and nuanced view of engagement provides necessary insight into the patterns and nature of contemporary Jewish life.

Segmenting a population into smaller groups based on shared characteristics is a foundational practice in the field of marketing (Smith 1956) and has been used to understand religious behavior as well (e.g., Kulis and Tsethlikai 2016; Pearce et al. 2013; Smith and Snell 2009). Recognizing the increasing diversity and complexity of Jewish life, some Jewish organizations are already attempting to segment their constituencies into groups with distinct behavioral patterns and then create different tracks to serve those groups based on their respective needs and interests (e.g., 
Uram 2016). These efforts are based on experience and intuition, but do not utilize a systematic method to synthesize multiple types of behaviors and create statistically based classifications of the populations they serve.

Using the LCA approach, an index of Jewish engagement can be developed for any subpopulation of the Jewish community, whether that be in the context of a local Jewish community study, a survey of Jewish millennials, or participants in a particular program. Further research should explore the application of LCA to other surveys of the Jewish community. These efforts could include developing a common question bank that reflects a wide range of Jewish behaviors. A comparison of the resulting indexes will provide new insight into Jewish life and a richer language for comparing and contrasting groups than is currently available.

The index of Jewish engagement can help policy makers connect with groups "where they are" and target programs to the needs and interests of particular groups. In many cases, initiatives are tailored based solely on demographics: young adults, intermarried families, or empty nesters. Although these groups share demographic characteristics, their interest in various aspects of Jewish life varies widely. Using an index of Jewish engagement developed for a specific community or subpopulation, outreach to groups can be tailored based on their current level of participation and interests. This approach to measuring Jewish engagement may contribute to the overall goal of enhancing that engagement in its many forms.

Open Access This article is distributed under the terms of the Creative Commons Attribution 4.0 International License (http://creativecommons.org/licenses/by/4.0/), which permits unrestricted use, distribution, and reproduction in any medium, provided you give appropriate credit to the original author(s) and the source, provide a link to the Creative Commons license, and indicate if changes were made.

\section{Appendix}

See Table 7. 


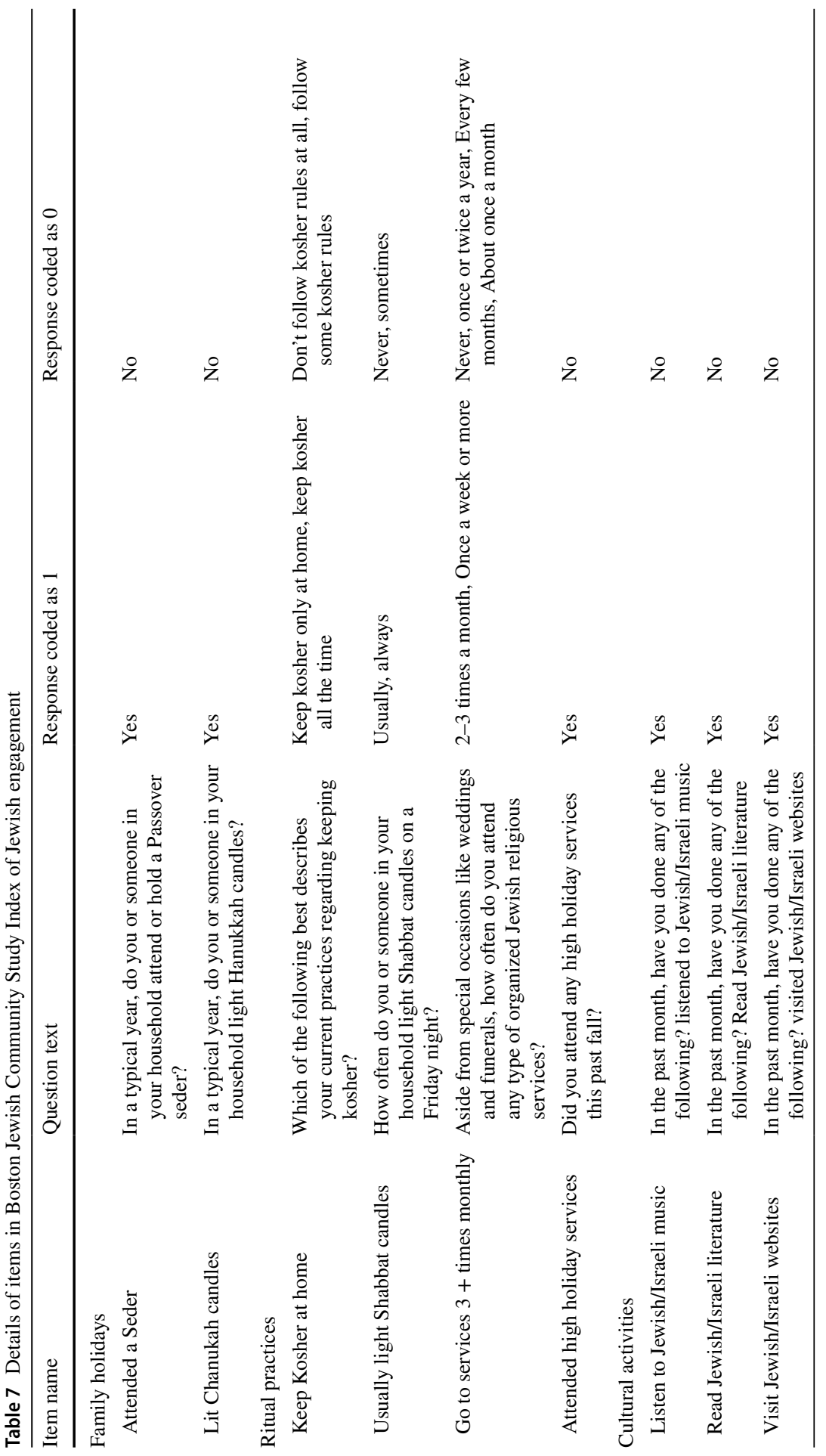




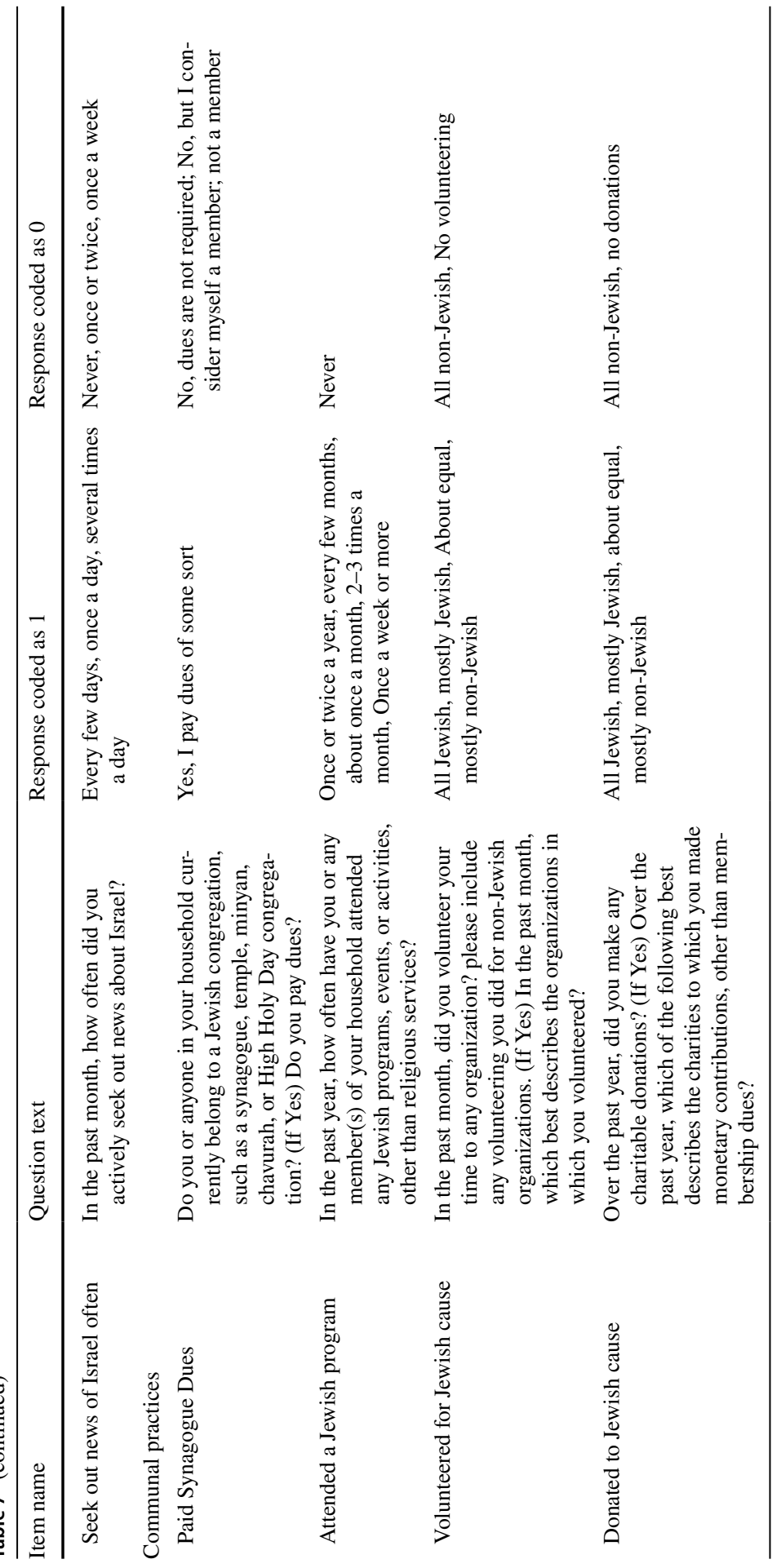




\section{References}

Aronson, Janet Krasner, Matthew Boxer, Matthew A. Brookner, Charles Kadushin, and Leonard Saxe. 2016. 2015 Greater Boston Jewish community study. Waltham, MA: Steinhardt Social Research Institute, Brandeis University.

Cohen, Steven M. 2015. The shrinking Jewish middle. In American Jewish year book 2014, vol. 114, ed. A. Dashefsky and I. Sheskin, 27-31. New York: Springer.

Cohen, Steven M., Jacob B. Ukeles, and Ron Miller. 2012. Jewish community study of New York: 2011 comprehensive report. New York: UJA-Federation.

Cox, Daniel, and Robert P. Jones. 2017. America's changing religious identity. PRRI. Retrieved from https://www.prri.org/research/american-religious-landscape-christian-religiously-unaffiliated. Accessed 17 Sept 2017.

eJewishPhilanthropy. 2015. Strategic directions for Jewish life: A call to action. Retrieved from http:// ejewishphilanthropy.com/strategic-directions-for-jewish-life-a-call-to-action/. Accessed 10 Oct 2015.

Gans, Herbert J. 1979. Symbolic ethnicity: The future of ethnic groups and cultures in America. Ethnic and Racial Studies 2(1): 1-20.

Graham, David J. 2014. The impact of communal intervention programs on Jewish identity: An analysis of Jewish students in Britain. Contemporary Jewry 34(1): 31-57.

Hartman, Harriet. 2014. Studies of Jewish identity and continuity in the United States: Competing, complementary, and comparative perspectives. In Studies in Contemporary Jewry, vol. 27, ed. Uzi Rebhun, 74-108. New York: Oxford University Press.

Hartman, Moshe, and Harriet Hartman. 1996. Are we one? How Jewish involvement is related to gendered patterns of secular achievement. In Gender equality and American Jews, ed. M. Hartman and H. Hartman, 197-207. Albany, NY: SUNY Press.

Hartman, Harriet, and Ira M. Sheskin. 2012. The relationship of Jewish community contexts and Jewish identity: A 22-community study. Contemporary Jewry 32(3): 237-283.

Hartman, Harriet, Ira M. Sheskin, and Erik Cohen. 2017. Multi-dimensional analysis of Jewish identity in 22 American Jewish communities. International Journal of Religions and Traditions 2(1): 19-31.

Henry, Neil W., and Paul F. Lazarsfeld. 1968. Latent structure analysis. Boston: Houghton Mifflin.

Himmelfarb, Harold S. 1982. Research on American Jewish identity and identification: Progress, pitfalls, and prospects. In Understanding American Jewry, ed. Marshall Sklare. Waltham: Brandeis University.

Horowitz, B. 1998. Connections and journeys: Shifting identities among American Jews. Contemporary Jewry 19(1): 63-94.

Institute of Medicine (IOM). 2014. Appendix A. In Chronic multisymptom illness in Gulf War veterans: Case definitions reexamined. Washington, DC: The National Academies Press.

Knight, Carly R., and Mary C. Brinton. 2017. One egalitarianism or several? Two decades of gender-role attitude change in Europe. American Journal of Sociology 122(5): 1485-1532.

Kosmin, Barry, Goldstein Sidney, Joseph Waksberg, Nava Lerer, Ariela Keysar, and Jeffrey Scheckner. 1991. Highlights of the CJF 1990 national population survey. New York: Council of Jewish Federations and Welfare Funds (CJF).

Kotler-Berkowitz, Laurence. 2016. The challenges of local Jewish community studies: An introduction. Contemporary Jewry 3(36): 289-295.

Kulis, Stephen S., and Monica Tsethlikai. 2016. Urban American Indian youth spirituality and religion: A latent class analysis. Journal for the Scientific Study of Religion 55(4): 677-697. https://doi. org/10.1111/jssr.12298.

Lanza, Stephanie T., John J. Dziak, Liying Huang, Aaron T. Wagner, and Linda M. Collins. 2015. LCA stata plugin users' guide (version 1.2). University Park, Penn State: The Methodology Center.

Lazar, Aryeh, Shlomo Kravetz, and Peri Frederich-Kedem. 2002. The multidimensionality of motivation for Jewish religious behavior: Content, structure, and relationship to religious identity. Journal for the Scientific Study of Religion 41(3): 509-519.

Pearce, Lisa D., E. Michael Foster, and Jessica Halliday Hardie. 2013. A person-centered examination of adolescent religiosity using latent class analysis. Journal for the Scientific Study of Religion 52(1): 57-79. https://doi.org/10.1111/jssr.12001.

Pew Research Center. 2013. A portrait of Jewish Americans. Washington, DC: Pew Forum on Religion \& Public Life. 
Pew Research Center. 2017a. Political typology reveals deep fissures on the right and left. Washington, DC: Pew Research Center.

Pew Research Center. 2017b. A portrait of American Orthodox Jews: A further analysis of the 2013 survey of US Jews. In American Jewish year book 2016: The annual record of North American Jewish communities, vol. 116, ed. Arnold Dashefsky and Ira M. Sheskin, 9-29. New York: Springer.

Rebhun, Uzi. 2004. Jewish identity in America: Structural analyses of attitudes and behaviors. Review of Religious Research 46(1): 43-63. https://doi.org/10.2307/3512252.

Sasson, Theodore, Janet Krasner Aronson, Fern Chertok, Charles Kadushin, and Leonard Saxe. 2017. Millennial children of intermarriage: Religious upbringing, identification, and behavior among children of Jewish and non-Jewish parents. Contemporary Jewry 37(1): 99-123. https://doi. org/10.1007/s12397-017-9202-0.

Saxe, Leonard, and Elizabeth Tighe. 2013. Estimating and understanding the Jewish population in the United States: A program of research. Contemporary Jewry 33: 43-62.

Saxe, Leonard, Theodore Sasson, and Janet Krasner Aronson. 2014a. Pew's portrait of American Jewry: A reassessment of the assimilation narrative. In American Jewish year book 2014, vol. 114, ed. Arnold Dashefsky and Ira Sheskin, 71-81. New York: Springer.

Saxe, Leonard, Elizabeth Tighe, and Matthew Boxer. 2014b. Measuring the size and characteristics of American Jewry: A new paradigm to understand an ancient people. In Studies in contemporary Jewry, vol. 28, ed. Uzi Rebhun. New York: Oxford University Press.

Sheskin, Ira M., and Arnold Dashefsky. 2017. United States Jewish population, 2016. In American Jewish year book 2016, ed. A. Dashefsky and I.M. Sheskin, 153-239. Cham: Springer.

Smith, Wendell R. 1956. Product differentiation and market segmentation as alternative marketing strategies. Journal of Marketing 21(1): 3-8. https://doi.org/10.2307/1247695.

Smith, Christian, and Patricia Snell. 2009. Souls in transition: The religious and spiritual lives of emerging adults. Oxford: Oxford University Press.

Uram, Mike. 2016. Next generation Judaism: How college students and Hillel can help reinvent Jewish organizations. Nashville, TN: Jewish Lights Publishing.

Wertheimer, Jack, and Steven M. Cohen. 2014. The Pew survey reanalyzed: More bad news, but a glimmer of hope. New York: Mosaic.

Janet Krasner Aronson is an associate director and associate research scientist at the Cohen Center for Modern Jewish Studies and Steinhardt Social Research Institute at Brandeis University. She is a co-author of the 2015 Greater Boston Jewish Community Study.

Leonard Saxe is Klutznick Professor of Contemporary Jewish Studies and directs the Cohen Center for Modern Jewish Studies and the Steinhardt Social Research Institute at Brandeis University. He is the recipient of the 2012 Marshall Sklare Award. He is a co-author of the 2015 Greater Boston Jewish Community Study.

Charles Kadushin is Professor Emeritus Sociology, Graduate Center, CUNY; Distinguished Scholar, Cohen Center for Modern Jewish Studies and Visiting Research Professor, Department of Sociology, Brandeis University. He has also taught at Columbia University in the Sociology and Social Psychology Departments and at Yale University in the School of Management and in Graduate Sociology. He is a coauthor of the 2015 Greater Boston Jewish Community Study.

Matthew Boxer is an assistant research professor at the Cohen Center for Modern Jewish Studies, the Steinhardt Social Research Institute, and the Hornstein Jewish Professional Leadership Program. He is a co-author of the 2015 Greater Boston Jewish Community Study.

Matthew A. Brookner is a graduate research associate at the Cohen Center for Modern Jewish Studies and Steinhardt Social Research Institute and is a doctoral student at the Heller School for Social Policy and Management at Brandeis University. He is a co-author of the 2015 Greater Boston Jewish Community Study. 